\title{
Burden and costs of migraine in a Swedish defined patient population - a questionnaire-based study
}

\author{
Frida Hjalte ${ }^{1 *+} \mathbb{D}$, Sara Olofsson ${ }^{1 \dagger}$, Ulf Persson $^{1}$ and Mattias Linde 2,3
}

\begin{abstract}
Background: Migraine is a disabling, chronic neurological disease leading to severe headache episodes affecting 13.2\% of the Swedish population. Migraine leads to an extensive socio-economic burden in terms of healthcare costs, reduced workforce and quality of life (QoL) but studies of the health-economic consequences in a Swedish context are lacking.

The objective of this study is to map the health-economic consequences of migraine in a defined patient population in terms of healthcare consumption, production loss and QoL in Sweden.

Methods: The study is based on data from a web-based survey to members in the Swedish patients' association suffering from migraine. The survey was conducted in May 2018 and included people with migraine aged 18 years or older. The survey included questions on health resource consumption, lost production resulting from migrainerelated absenteeism and presenteeism, and QoL as measured by the EuroQol 5 dimensions questionnaire (EQ-5D-5 $\mathrm{L})$ and the Headache Impact Test (HIT-6). The results are presented in yearly costs per patient and losses in quality adjusted life years (QALYs).
\end{abstract}

Results: The results are based on answers from 630 individuals with migraine and are presented by number of migraine days per month. The total cost per patient and year increased with the number of migraine days per month $(p<0.001)$ and varied between approximately $€ 5000$ for those with less than 3 migraine days per month and $€ 24,000$ per year for those with 21-28 migraine days per month. Production loss represented the main part of the costs, approximately $80 \%$. The average loss in QALYs per year also increased with the monthly number of migraine days $(p=0.023)$.

Conclusions: Migraine leads to significant societal costs and loss of quality of life. There appears to be an unmet need and a potential for both cost savings and QoL benefits connected with a reduction in the number of migraine days.

Keywords: Migraine, Cost, Work productivity, Quality of life, EQ-5D, Sweden

\section{Background}

Migraine is a disabling, chronic neurological disease characterized by severe headache episodes with throbbing pain in combination with nausea, vomiting, light sensitivity (photophobia) and sound sensitivity (phonophobia) [1]. $13.2 \%$ of the Swedish population suffers from migraine and the disease is more common among women (16.7\%) than among men (9.5\%) [2]. In a previous study of the

\footnotetext{
* Correspondence: fh@ihe.se

${ }^{\dagger}$ Frida Hjalte and Sara Olofsson contributed equally to this work.

${ }^{1}$ The Swedish Institute for Health Economics (IHE), Lund, Sweden

Full list of author information is available at the end of the article
}

disease burden of migraine in Sweden, people with migraine had on average 1.3 migraine episodes per month, which lasted for $19 \mathrm{~h}$ on average [3]. A majority (65\%) reported absence from school or work in the past year due to migraine and over 50\% reported that migraine affected leisure time, family situation and work ability.

Chronic migraine $(\mathrm{CM})$ is defined in accordance with the International Classification of Headache Disorders (ICHD-3) as at least 15 headache days per month, of which at least 8 with migraine [4]. Episodic migraine can be divided into low frequency and high frequency depending on the number of headache days per month where 
low frequency has been defined as 1-9 days a month and high frequency as 10-14 days per month [5]. About 1-2\% of the general population is estimated to have CM [6].

Migraine pharmacological treatment consists of both acute and preventive therapies. Acute drugs include paracetamol, non-steroidal anti-inflammatory drugs (NSAIDs) and triptans [7]. Preventive drug treatments include beta blockers, angiotensin-2 inhibitors, antiepileptics, antidepressants and botulinum toxin type A [7]. Preventive treatment usually does not render the patient migraine free but can lead to reduced frequency of migraine days and milder symptoms.

Evidence-based nonpharmacological therapeutic alternatives for treating migraine include nutraceuticals (e g. riboflavin), invasive and non-invasive neuromodulation and different behavioural techniques and acupuncture [8].

Several studies have shown that migraine leads to an extensive socio-economic burden in terms of direct costs, i.e. resources required for health care and treatment [9], indirect costs, i.e. the value of the lost production resulting from migraine-related absenteeism and presenteeism (reduced productivity at work related to migraine) $[10,11]$ and reduced quality of life (QoL) [11-15]. An earlier European study has reported yearly health care costs related to migraine between $€ 500$ and 3700 per person depending on country and migraine frequency [9]. The average societal cost of migraine in eight European countries has previously been reported to more than $€ 1200$ per person and year where production loss accounted for the main part [10]. Previous studies show that the disease burden varies widely between different countries. However, studies analysing health-economic consequences in a Swedish context are lacking.

The primary objective of this study was to map the health-economic consequences of migraine in a defined patient population in terms of healthcare consumption, production loss and QoL in Sweden based on a survey of people with migraine. The secondary objective is to investigate how these consequences vary with the number of days of migraine and other background characteristics.

\section{Method}

A survey was conducted in May 2018. The Swedish patients' association, Huvudvärksförbundet, sent out a link to a web-page with the questionnaire to all members with a registered e-mail address, a total of 2894 individuals. Two reminders were sent. Inclusion criteria were having migraine (no specific diagnosis criteria) and being 18 years or older. The respondents were not reimbursed for their participation.

The web-based questionnaire was designed to include questions about age, gender, migraine duration, migraine frequency, diagnoses, number of visits to physicians and visits to other healthcare providers due to migraine, acute drug treatment and preventive drug treatment, sickness absence and QoL. QoL was measured by the generic instrument, Euro-Qol 5 dimensions - 5 levels (EQ-5D-5 L) [16], and a disease-specific instrument, HIT-6 (Headache Impact Test) [17]. The EQ-5D is widely used to measure health-related QoL in health economics analyses. Respondents were asked to assess their current health status using EQ-5D-5 L followed by a question on whether they currently suffered from a migraine episode or not. Depending on the response, the respondent was instructed to recall their last day with/without migraine and again respond to questions on the health status of that day using EQ-5D-5 L.

The number of health care visits and the use of preventive drug treatment were asked with a 12 month recall period while acute drug treatment and sickness absence were asked with a 4 week recall period. Due to the natural course of the disease which is characterized by "ad hoc" ictal phases it was assumed that it would be more difficult for respondents to recall their long-term use of acute drug treatment as well as sickness absence beyond a 4 week recall period.

The results are presented by number of migraine days per month using the following categories; $0,{ }^{1} 1-3,4-5$, $6-7,8-9,10-14,15-20$ and $21-28$ days. Health care costs were calculated by multiplying the resource use reported in the survey with unit prices from a regional price list for the Southern Health Care Region in 2018 [18], which is one of the most detailed sources of information on the costs of health care resources in Sweden. Pharmaceutical costs were calculated according to AUP prices (retail/pharmacy-level prices) from Pharmaceutical Specialties in Sweden (FASS) [19]. The production loss due to short-term work absenteeism was calculated by multiplying days of sick leave by the sex- and age adjusted average wage including pay roll taxes in accordance with the human capital approach [20]. The production loss due to long-term work absenteeism was based on the assumption that respondents with migraine and long-term sick-leave would have had the same productivity as the general population (of corresponding age and sex) if they would have been free of migraine. Production loss due to reduced presenteeism was likewise calculated but multiplied with the point estimate from the VAS scale (from 0 to 10), where the respondent indicated to what extent productivity was reduced while working with migraine. The calculation of total yearly costs for acute drugs and production loss assumed that the 1-month period reported was representative for the rest of the year, thus multiplying the monthly cost with 12 .

The loss of a Quality Adjusted Life Years (QALY) is calculated by multiplying QoL weights for a specific health state by the time spent in that health state. The loss in QoL considered both the loss caused by the chronic 
feature of migraine (interictal phase) and the loss caused by the migraine episode (ictal phase). Figure 1 illustrates this loss of a QALY related to migraine where the grey area illustrates the loss during the interictal state and the grey striped areas represent the QALY loss during ictal phases. The QoL weights used in this study are derived from Devlin et al. 2018 [21]. The QoL weights for the general population (baseline estimates) are derived from Dolan et al. 1995 [22]. The reason for different weights is that this study used the EQ-5D-5 L while the study of the Swedish general population [23] used the EQ-5D-3 L.

Differences were assessed using t-test. A $p$-value below 0.05 was considered statistically significant.

An OLS (Ordinary Least Squares) regression was performed to identify predictors of costs and the loss of QALYs related to migraine.

All costs were calculated in Swedish krona (SEK), 2017 prices, and converted to Euros (SEK $1=€ 0.089$ ).

Data management and statistical analyses were performed using STATA Statistical Software: Release version 14.2 College Station, Texas, USA.

Ethical approval for the study was obtained by the Regional Ethical Board in Lund in 2018 (Dnr 2018/347). Informed consent was obtained from all individuals included in the study.

\section{Results}

Out of the 2894 individuals who received the questionnaire, 795 individuals responded and met the inclusion criteria.
From those who responded 630 completed the questionnaire. The results in the study are based on the 630 answers.

Table 1 presents background characteristics of the individuals included in the study. The average age of respondents was 50 years and the majority were women (87.8\%). A majority (85.2\%) of respondents had suffered from migraine for over 15 years. Nearly all respondents (96.4\%) had been diagnosed by a doctor and almost half (46.5\%) had been diagnosed with CM.

Over the last 4 weeks, $6.8 \%$ of the respondents had no days of migraine, $55.6 \%$ had $1-7$ days and $37.6 \%$ had more than 8 days with migraine (Fig. 2). Around $22.2 \%$ had CM based on self-reported number of migraine and headache days. Mean number of days with headache for all respondents was 12 days, including 7 days of migraine activity over the last 4 weeks. More than half of respondents had a migraine episode lasting less than $24 \mathrm{~h}$. $52.9 \%$ of the respondents reported that last 4 weeks corresponded to an average month regarding migraine frequency, $30.4 \%$ reported it as a "better" month than average, and $14.3 \%$ that the last month was "worse" than an average month.

During the last 12 months, $44.8 \%$ of the respondents had visited a neurologist and $45.4 \%$ had visited a general practitioner in primary care. Almost one third of the respondents had visited a physiotherapist during the last 12 months. The most common examinations, related to migraine, were blood test and MRI (magnetic resonance imaging) (Table 2).

The health care costs varied between $€ 800$ for those with less than 4 migraine days per month and up to

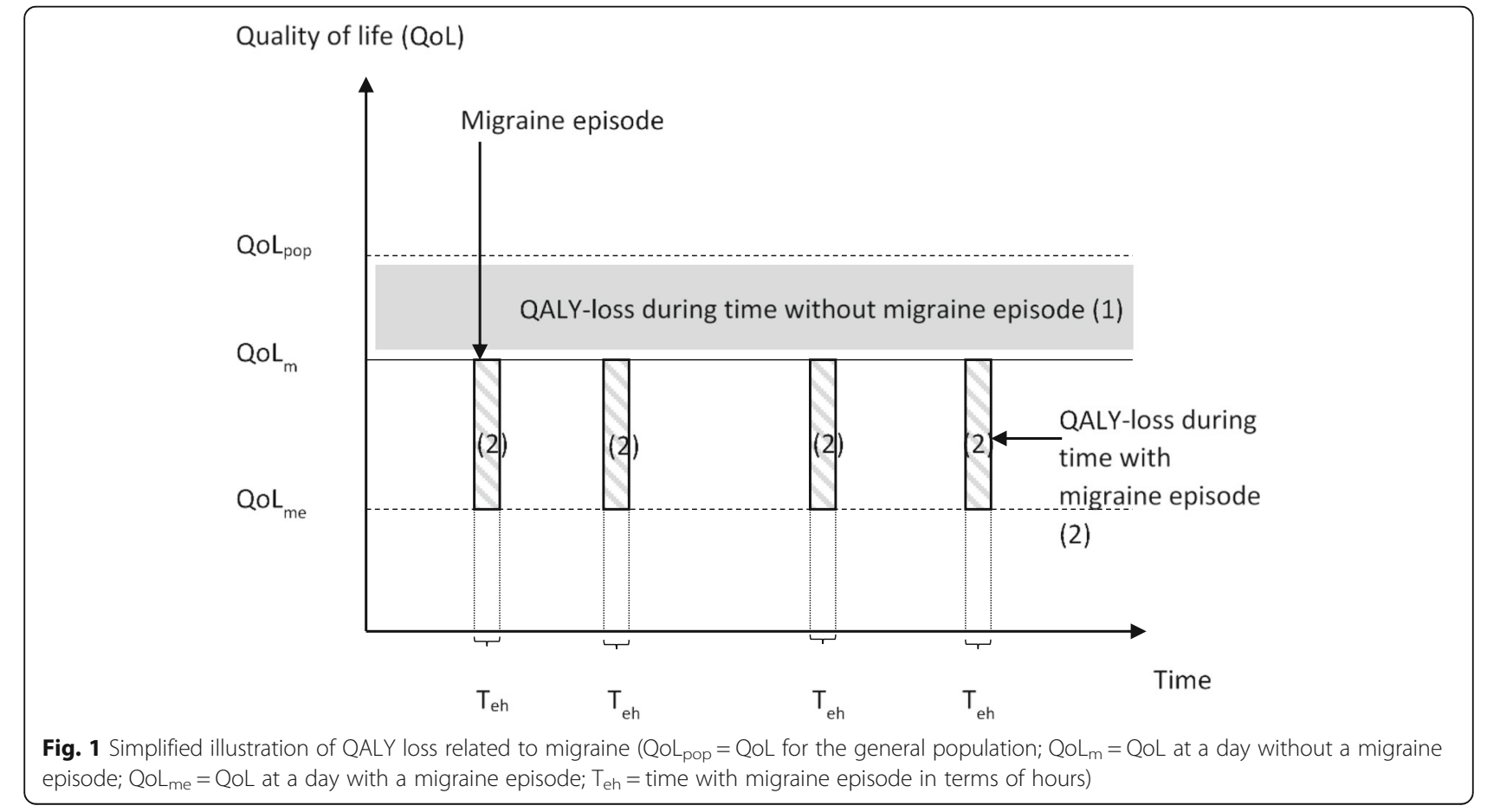


Table 1 Background characteristics

\begin{tabular}{|c|c|}
\hline & $n=630$ \\
\hline Age, mean (SD) & $50.1(11.7)$ \\
\hline Women (\%) & $553(87.8)$ \\
\hline \multicolumn{2}{|l|}{ Level of education (\%) } \\
\hline Elementary school & $15(2.4)$ \\
\hline Secondary school & $170(27.3)$ \\
\hline University & $406(65.3)$ \\
\hline Other & $31(5.0)$ \\
\hline \multicolumn{2}{|l|}{ Occupation (\%) } \\
\hline Employed or self-employed & $479(76.0)$ \\
\hline Student & $11(1.8)$ \\
\hline Retired & $78(12.4)$ \\
\hline Sick-leave & $30(4.8)$ \\
\hline Unemployed & $15(2.4)$ \\
\hline Other & $17(2.7)$ \\
\hline \multicolumn{2}{|l|}{ Migraine duration (\%) } \\
\hline$<1$ year & $2(0.3)$ \\
\hline $1-5$ years & $12(1.9)$ \\
\hline $6-10$ years & $31(4.9)$ \\
\hline $11-15$ years & $48(7.6)$ \\
\hline$>15$ years & $537(85.2)$ \\
\hline Diagnosis by doctor, $n(\% \text { of all) })^{b}$ & $607(96.4)$ \\
\hline Migraine with aura & $202(32.1)$ \\
\hline Migraine without aura & $282(44.8)$ \\
\hline Chronic migraine & $293(46.5)$ \\
\hline Episodic migraine & $46(7.3)$ \\
\hline Other/don't know & $91(14.4)$ \\
\hline Other disease, $\mathrm{n}$ (\% of all) ${ }^{\mathrm{b}}$ & $361(57.3)$ \\
\hline Consequence of previous trauma or head surgery & $23(3.7)$ \\
\hline Cardiovascular disease & $26(4.1)$ \\
\hline Psychiatric disease & $139(22.1)$ \\
\hline Sleep disorder & $85(13.5)$ \\
\hline Allergy & $122(19.4)$ \\
\hline Other headache diagnosis & $95(15.1)$ \\
\hline Other & $224(35.6)$ \\
\hline HIT-6, mean $(S D)^{c}$ & $63.7(5.5)$ \\
\hline
\end{tabular}

${ }^{a} n=622,{ }^{b}$ More than one diagnosis or disease possible, 'Scale: 36 (never problem of all dimensions) to 78 (always problem at all). $60+$ corresponds to "severe impact"

$€ 4000$ for those who had at least 15 migraine days per month. The costs for visits to emergency rooms and inpatient days were almost exclusively accounted for by patients with migraine at least 15 days per month.

The most common acute drug was sumatriptan followed by paracetamol. The most common preventive drug was botulinum toxin type A (e.g. Botox $\left.{ }^{\circ}\right)$, used by $39.7 \%$ of respondents. $35.4 \%$ of the respondents indicated that they were not satisfied with their treatment, while $25.9 \%$ responded that they were satisfied. A majority (56.0\%) had changed drug treatment or terminated treatment at least once, and $27.0 \%$ had changed drug treatment or terminated treatment at least three times.

Among all respondents with an employment or with self-employment $76.2 \%(n=366)$ reported sick leave at some point during the last 12 months. On average, the respondents had reported 22 days of sick leave during the last 12 months. Eighty-nine percent $(n=429)$ stated that they worked in average 30 days while having migraine (presenteeism) during the last 12 months. In addition to the reported short-term sick leave, $17.9 \%$ of all respondents reported long-term sick leave. The total production loss increased with the number of migraine days.

The total cost per patient and year increased with the number of migraine days per month (Fig. 3) and varied between $€ 5000$ and $€ 24,000$ per year. The average total cost per patient and year for all respondents amounts to $€ 10,790$. Indirect costs represented the main part of the costs, about $80 \%$. The average total cost per patient and year for respondents with chronic migraine (defined as at least 15 headache days per month, whereof at least 8 days with migraine) was almost three times higher compared to the average total cost per patient and year for respondents with episodic migraine ( $€ 21,782$ vs. $€ 7598, p<0.001)$. Both the number of headache and migraine days had a statistically significant impact on the total cost per person and year $(p<0.01)$. Other variables associated with total cost included age, employment, chronic migraine diagnosis and treatment with botulinum toxin (Additional file 1).

The difference in reported QoL between a day with and without migraine was $0.36(p<0.001)$ (Table 3$)$. As showed in Table 3, the difference was less for those who responded to the questionnaire while having migraine (observable) compared to them who responded while not having migraine, thus recalling their health status the last day with migraine (retrospective).

The average loss in QALYs per person and years increased with the number of migraine days per month and varied between 0.019 and 0.259 QALYs (Fig. 4). The total average loss in QALYs per person and year was 0.10 and significantly higher for respondents with chronic migraine compared to respondents with episodic migraine $(0.25$ vs. $0.06, p<0.001)$. The increase was most noticeable for the loss during the time without migraine episode (interictal state). The increase in the loss due to migraine episodes was limited because the baseline QoL (i.e. during a day without a migraine episode) for respondents with frequent migraine was already low. Both the number of headache and migraine days had a statistically significant impact on the loss in QALYs per person and year $(p=0.002, p=0.023$, data in Additional file 1). 


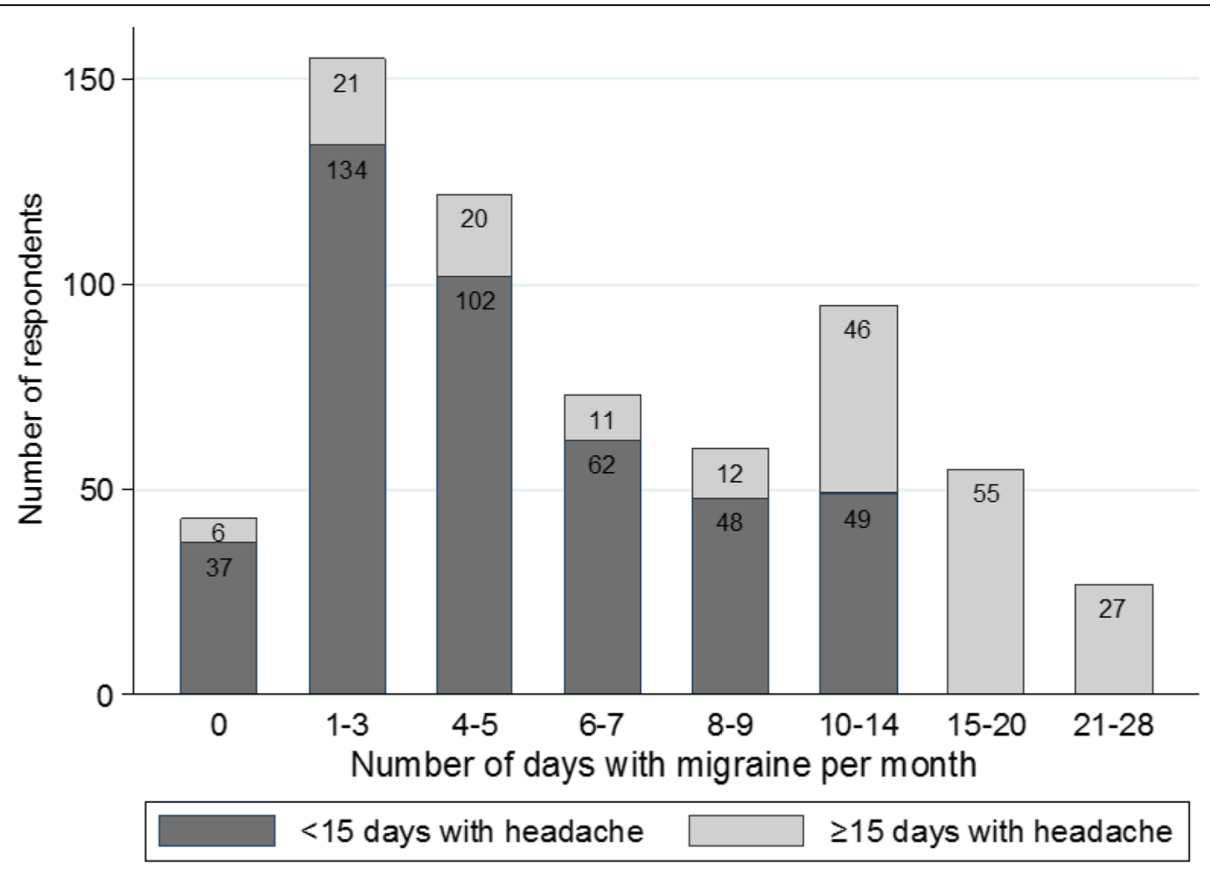

Fig. 2 Number of respondents by number of migraine days per month divided into groups with $<15$ and $\geq 15$ headache days per month

\section{Discussion}

This study shows that migraine leads to significant societal costs and loss of QoL. The average total cost per person and year was $€ 10,790$ and the average total QALY-loss per person and year was 0.10 . The results of the analyses also show that both costs and loss in QoL increase with the number of headache and migraine days. Chronic migraine was associated with significantly higher cost, $€ 21,782$ vs. $€ 7598$, and QALY-loss, 0.25 vs. 0.06 , compared to episodic migraine.

A major strength of the study is that long-term consequences of migraine in terms of long-term reduction of productivity and QoL is captured. To our knowledge it is also one of the first studies analysing the health-economic consequences of migraine for a Swedish context. The study differs from earlier studies considering health-economic aspects of migraine in that almost all respondents had been diagnosed by a doctor.

Almost all respondents had been diagnosed with migraine by a doctor according to their self-reported answer. A previous study showed that only about $50 \%$ of the respondents with self-reported migraine had received a diagnosis from a doctor in Sweden [3]. Although diagnosis frequency may have increased, the results of this study are likely not generalizable to the whole group of migraine patients. However, diagnosed patients are the primary candidates for new treatments and the results are therefore still relevant for future health economic analyses. The migraine diagnosis could not be checked or verified. However, provided that the respondents had joined a patient organization for headache disorders it is reasonable to assume that most of them had been diagnosed by a doctor. There may be additional selection bias since the sample was identified from a patient organization, which may include the more active participants and/or individuals with more severe migraine. The proportion of people with diagnosed CM or a migraine duration of at least 15 years was also found to be significantly higher than stated in other studies $[3,10]$. The response rate may seem extremely low (22\%). However, the questionnaire was sent to all members of Huvudvärksförbundet which includes individuals with different kinds of headache disorders. The real response rate could not be calculated since there were no information on the number of members with migraine.

This study is retrospective, i.e. respondents reported migraine experience, resource consumption and QoL for a period back in time. This implies a risk of recall bias which suggests caution in the interpretation of results. For example, in the QoL reporting there may be a recall bias in those with low frequency (e.g. if the last migraine day occurred some weeks before) as well as in those with high frequency (e.g. if the last day without migraine occurred weeks before). However, half of respondents reported that they used a migraine diary. Almost all reported at least one migraine day during the last 4 weeks. Information on headache and migraine frequency during the last 4 weeks was expanded to the entire year. This may cause some bias due to the migraine variability over time. For a majority (85\%) the last 4 weeks had been as good or better than an average month, which means that the estimation is likely to be an underestimation. 
Table 2 Health care visits, examinations and drugs related to migraine during the last 12 months

\begin{tabular}{|c|c|c|}
\hline Type of health care & $\begin{array}{l}\text { Number of } \\
\text { respondents (\%) } \\
(n=630)\end{array}$ & $\begin{array}{l}\text { Mean number of visits/ } \\
\text { examinations (SD) }\end{array}$ \\
\hline Visits & $57(9)$ & $2.8(8.0)$ \\
\hline \multicolumn{3}{|l|}{ Emergency room visit } \\
\hline Neurologist & $282(45)$ & $3.0(2.2)$ \\
\hline $\begin{array}{l}\text { General practitioner, } \\
\text { primary care }\end{array}$ & $286(45)$ & $2.8(2.7)$ \\
\hline Other doctor & $53(8)$ & $2.3(2.0)$ \\
\hline Nurse & $75(12)$ & $4.1(5.5)$ \\
\hline Physiotherapist & $184(29)$ & $9.6(11.9)$ \\
\hline Occupational therapist & $24(4)$ & $2.9(3.3)$ \\
\hline Psychologist & $57(9)$ & $6.2(6.6)$ \\
\hline Social worker & $32(5)$ & $5.1(4.5)$ \\
\hline Other & $84(13)$ & $8.2(8.5)$ \\
\hline Inpatient stay (days) & $14(2)$ & $5.5(5.9)$ \\
\hline \multicolumn{3}{|l|}{ Examinations } \\
\hline $\begin{array}{l}\text { MRI (magnetic resonance } \\
\text { imaging) }\end{array}$ & $66(10)$ & $1.0(0.5)$ \\
\hline $\begin{array}{l}\text { CT scanning (computer } \\
\text { tomography) }\end{array}$ & $39(6)$ & $1.0(0.5)$ \\
\hline ECG (Electrocardiography) & $46(7)$ & $1.5(1.0)$ \\
\hline Bloodtest & $147(23)$ & $2.2(2.3)$ \\
\hline Other & $41(7)$ & $1.9(1.4)$ \\
\hline \multicolumn{3}{|l|}{ Drugs } \\
\hline Acute drugs & $588(93)$ & \\
\hline Preventive drugs & $278(44)$ & \\
\hline
\end{tabular}

There might also be a risk of bias in the QoL calculation as the reporting of both observable and retrospective EQ-5D might magnify the difference between the ictal and interictal phases, i.e. people might underestimate their QoL at the last attack compared to the current non-migraine day. The comparison of observable and retrospective responses demonstrated that observable responses gave a lower decrease in QoL. This result is consistent with the difference reported in other studies measuring QoL hypothetically (ex ante) [22] and observable (ex post) [24]. The hypothetical QoL is generally considered more relevant to decision making since it is assessed in a situation before suffering while the observable assessment implies an adaptation to the health state. The weights used for the baseline health state (assumed to correspond to age- and sex adjusted QoL reported for the Swedish general population) were different from the weights used for the ictal and interictal phases. This may have caused some bias in the estimation of the QALY loss during the time without a migraine episode (interictal phases). Since there are no studies using EQ-5D-5 L for the Swedish general population, it is difficult to estimate to what extent this is a source of bias. However, the utility weights used were relatively high (between 0.74 and 0.91 ) and studies comparing different types of weights do not find much differences at this level [25].

In our study, the annual healthcare cost of $\mathrm{CM}$ was estimated to around $€ 3668$ per person and the annual cost of episodic migraine was estimated to approximately $€ 1331$. The results are in the upper range of results reported in a previous European study by Bloudek et al. 2012, covering data from the UK, France, Germany, Italy and Spain [9],

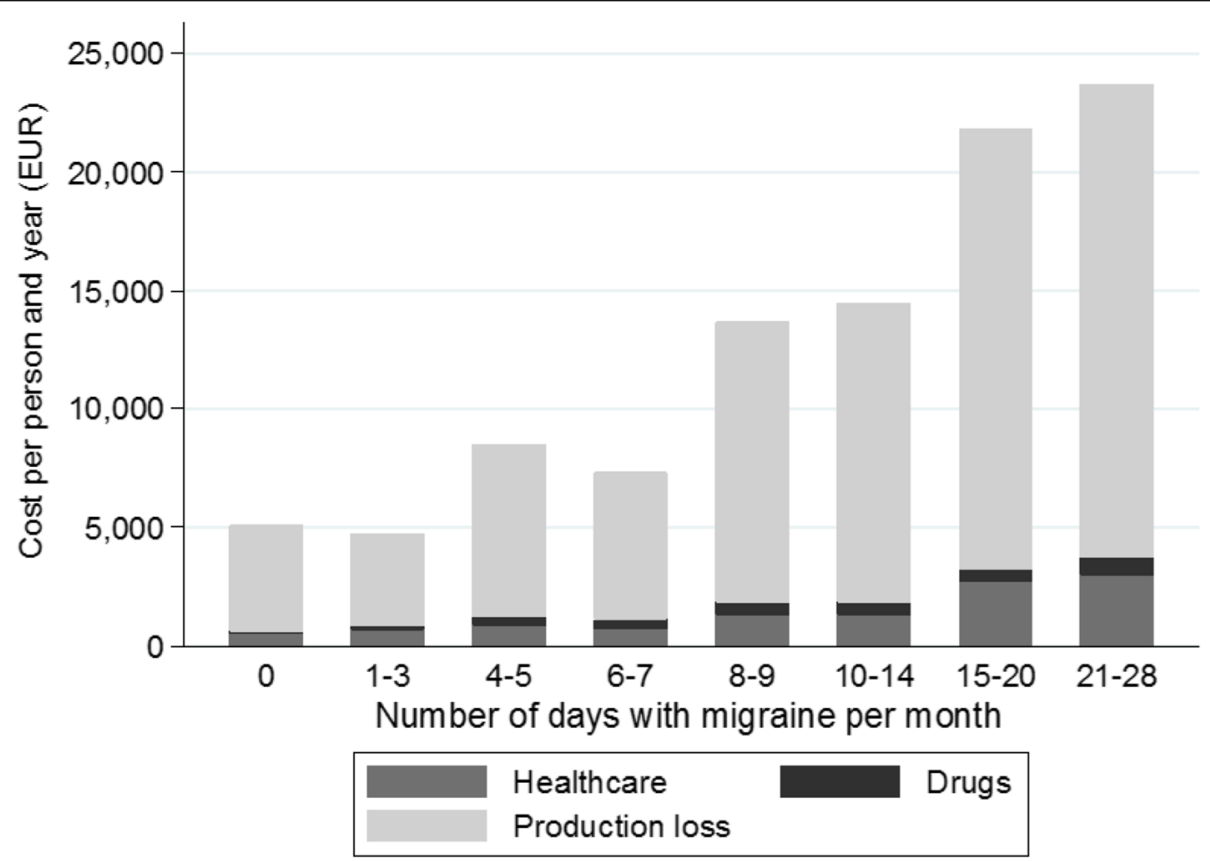

Fig. 3 Average total cost (EUR) per person and year by number of migraine days per month 
Table 3 Mean quality of life a day with migraine and a day without migraine

\begin{tabular}{|c|c|c|c|c|}
\hline & Day without migraine & Day with migraine & Difference & $p$-valuec \\
\hline \multicolumn{5}{|l|}{ EQ-5D } \\
\hline \multirow[t]{2}{*}{ All } & $0.786(0.219)$ & $0.422(0.337)$ & $0.364(0.318)$ & $<0.001$ \\
\hline & $N=630$ & $N=630$ & & \\
\hline \multirow[t]{2}{*}{ Observable $^{a}$} & $0.790(0.190)$ & $0.619(0.229)$ & 0.171 & $<0.001$ \\
\hline & $N=454$ & $N=176$ & & \\
\hline \multirow[t]{2}{*}{ Retrospective $^{b}$} & $0.775(0.253)$ & $0.346(0.341)$ & 0.429 & $<0.001$ \\
\hline & $N=176$ & $N=454$ & & \\
\hline \multicolumn{5}{|l|}{ EQ-VAS } \\
\hline \multirow[t]{2}{*}{ All } & $0.671(0.209)$ & $0.394(0.210)$ & $0.276(0.248)$ & $<0.001$ \\
\hline & $N=630$ & $N=630$ & & \\
\hline \multirow[t]{2}{*}{ Observable $^{a}$} & $0.677(0.189)$ & $0.496(0.215)$ & 0.181 & $<0.001$ \\
\hline & $N=454$ & $N=176$ & & \\
\hline \multirow[t]{2}{*}{ Retrospective $^{b}$} & $0.655(0.253)$ & $0.355(0.240)$ & 0.300 & $<0.001$ \\
\hline & $N=176$ & $N=454$ & & \\
\hline
\end{tabular}

${ }^{\mathrm{a}}$ Day without migraine $=$ Respondents reporting not having migraine when completing the questionnaire. Day with migraine = Respondents reporting having migraine when completing questionnaire

${ }^{\mathrm{b}}$ Day without migraine = Respondents reporting having migraine when completing questionnaire, asked to report for last day without migraine. Day with migraine $=$ Respondents reporting not having migraine when completing the questionnaire, asked to report for last day with migraine

'T-test

which might be explained by our study almost only including persons with a physician's diagnosis, while Bloudek et al. included a large amount of self-diagnosed persons.

The total societal cost in our study amounted to approximately $€ 10,790$ per person and year, i.e. almost ten times higher than reported in another European study Linde et al. 2012 covering eight different countries
(Austria, France, Germany, Italy, Lithuania, Luxembourg, Netherlands and Spain), € 1222 per person [10]. One reason for this substantial difference may be that both our and the study by Bloudek et al. included more respondents with a more severe type of migraine. Our study addressed members of the patient association, Bloudek et al. addressed a stratified sample of an internet panel who

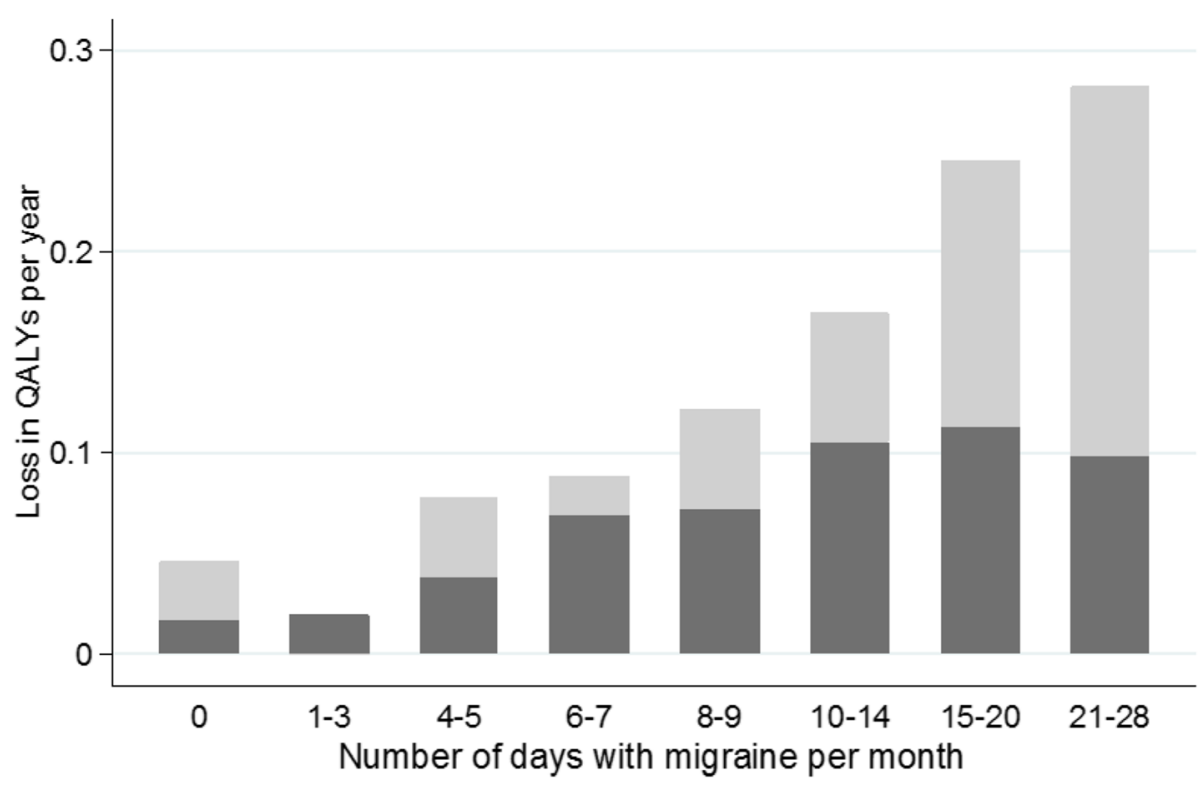

Loss due to migraine episode $\quad$ Loss du ring time with out migraine episode

Fig. 4 Average loss in QALYs per year and person by number of migraine days per month 
suffered from headaches while Linde et al. targeted people with self-reported migraine in samples of the general population.

The loss in QoL related to a migraine episode has previously been investigated with EQ-5D in the United States (US) [15] and the United Kingdom (UK) [13]. The US study allowed respondents to complete the EQ-5D during a migraine episode and a day after treatment initiation. The loss in QoL was 0.14 for those with mild migraine, 0.19 for those with moderate migraine and 0.49 for those with severe migraine. In the UK study, people with migraine retrospectively completed EQ-5D for different levels of severity during one single migraine episode resulting in a loss in QoL of 0.21 for mild migraine, 0.34 for moderate migraine and 1.07 for severe migraine. In our study, the loss in QoL was estimated to 0.36. Based on HIT-6, the people who answered in our study had a severe form of migraine. This loss in QoL is lower than in the US and the UK. For the US study, this might be explained by the fact that the respondents assessed their QoL 1 day after initiation of treatment. Possibly, the QoL is then perceived higher than in general due to the current pain relief. In the UK study, the respondents assessed their QoL at a time of the migraine episode when feeling the worst. In our study, respondents reported QoL during a whole migraine episode. Comparisons between countries should however be interpreted with caution as they often differ due to other reasons.

\section{Conclusions}

This study shows that migraine represents a significant burden on society and the individual and that there is a need for new and better treatment options in migraine. Both costs and loss in quality of life increases with the number of migraine days. Thus, there is potential for both cost savings and quality of life benefits connected with a reduction in the number of headache and migraine days.

\section{Endnote}

${ }^{1}$ No migraine during the last 4 weeks, but migraine reported during the last year.

\section{Additional file}

Additional file 1: Table S1. Mean cost (SEK) per patient and year. Table S2. Average loss in QALY per person and year. Table S3. Regression of total cost per person and year. Table S4. Regression of total loss in QALY per person and year. (DOCX $32 \mathrm{~kb}$ )

\section{Abbreviations}

CM: Chronic migraine; COl: Cost-of-illness; EQ-5D: Euro-Qol 5 dimensions; FASS: Pharmaceutical specialties in Sweden; HIT-6: Headache impact test; NSAID: Non-steroidal anti-inflammatory drugs; QALY: Quality adjusted life years; QoL: Quality of life

\section{Acknowledgements}

The authors would like to thank both representatives for

Huvudvärksförbundet for important insights and support during the design and implementation of the study and all the participants of the study.

\section{Funding}

Sponsorship and article processing charges for this study were funded by Teva, Sweden.

\section{Availability of data and materials}

The datasets generated and analysed during the current study are not publicly available due to ethical approval which not allow the sharing of individual data.

\section{Authors' contributions}

$\mathrm{FH}, \mathrm{SO}$ and UP designed the study. FH and SO analysed the data and drafted manuscript. ML provided clinical expertise. FH, SO, UP and ML interpreted the results. All authors read and approved the final manuscript.

Ethics approval and consent to participate

Ethical approval for the study was obtained by the Regional Ethical Board in Lund in 2018 (Dnr 2018/347). Informed consent was obtained from all patients included in the study.

\section{Consent for publication}

Only deidentified data was available for analyses and the results are only presented on an aggregated level. Ethical approval for the study was obtained and each participating person signed an informed consent before participating.

\section{Competing interests}

$\mathrm{FH}, \mathrm{SO}$ and UP have no competing interests.

ML is director of Tjörn Headache Clinic in Sweden.

\section{Publisher's Note}

Springer Nature remains neutral with regard to jurisdictional claims in published maps and institutional affiliations.

\section{Author details}

${ }^{1}$ The Swedish Institute for Health Economics (IHE), Lund, Sweden. ${ }^{2}$ Department of Neuromedicine and Movement Sciences, NTNU Norwegian University of Science and Technology, Trondheim, Norway. ${ }^{3}$ Tjörn Headache Clinic, Tjörn, Rönnäng, Sweden.

Received: 7 February 2019 Accepted: 13 May 2019

Published online: 31 May 2019

\section{References}

1. Läkemedelsverket. Behandlingsrekommendation, Behandling av migrän [Available from: https://lakemedelsverket.se/upload/allmanhet/ behandlingsrekommendationer/Migran.pdf. Accessed 28 June 2018.

2. Dahlof C, Linde M (2001) One-year prevalence of migraine in Sweden: a population-based study in adults. Cephalalgia 21(6):664-671

3. Linde M, Dahlof C (2004) Attitudes and burden of disease among selfconsidered migraineurs--a nation-wide population-based survey in Sweden. Cephalalgia 24(6):455-465

4. Headache Classification Committee of the International Headache S (2013) The international classification of headache disorders, 3rd edition (beta version). Cephalalgia 33(9):629-808

5. Torres-Ferrus M, Quintana M, Fernandez-Morales J, Alvarez-Sabin J, PozoRosich P (2017) When does chronic migraine strike? A clinical comparison of migraine according to the headache days suffered per month. Cephalalgia 37(2):104-113

6. Natoli JL, Manack A, Dean B, Butler Q, Turkel CC, Stovner L et al (2010) Global prevalence of chronic migraine: a systematic review. Cephalalgia 30(5):599-609

7. internetmedicin.se. Migrän 2017 [Available from: https://www. internetmedicin.se/page.aspx?id=251. Accessed 28 June 2018.

8. Puledda F, Shields K (2018) Non-pharmacological approaches for migraine. Neurotherapeutics 15(2):336-345 
9. Bloudek LM, Stokes M, Buse DC, Wilcox TK, Lipton RB, Goadsby PJ et al (2012) Cost of healthcare for patients with migraine in five European countries: results from the international burden of migraine study (BMMS). J Headache Pain 13(5):361-378

10. Linde M, Gustavsson A, Stovner LJ, Steiner TJ, Barre J, Katsarava Z et al (2012) The cost of headache disorders in Europe: the Eurolight project. Eur J Neurol 19(5):703-711

11. Vo P, Fang J, Bilitou A, Laflamme AK, Gupta S (2018) Patients' perspective on the burden of migraine in Europe: a cross-sectional analysis of survey data in France, Germany, Italy, Spain, and the United Kingdom. J Headache Pain 19(1):82

12. Brown JS, Neumann PJ, Papadopoulos G, Ruoff G, Diamond M, Menzin J (2008) Migraine frequency and health utilities: findings from a multisite survey. Value Health 11(2):315-321

13. Stafford MR, Hareendran A, Ng-Mak DS, Insinga RP, Xu R, Stull DE (2012) EQ5D-derived utility values for different levels of migraine severity from a UK sample of migraineurs. Health Qual Life Outcomes 10:65

14. Stewart WF, Lipton RB, Kolodner K, Liberman J, Sawyer J (1999) Reliability of the migraine disability assessment score in a population-based sample of headache sufferers. Cephalalgia 19(2):107-114 discussion 74

15. Xu R, Insinga RP, Golden W, Hu XH (2011) EuroQol (EQ-5D) health utility scores for patients with migraine. Qual Life Res 20(4):601-608

16. EuroQol. https://eurogol.org/. Accessed 1 Mar 2018.

17. Headache Impact Test (HIT-6). https://www.optum.com/solutions/lifesciences/answer-research/patient-insights/condition-specific-surveys.html. Accessed 3 May 2018

18. Södra regionvårdsnämnden. Regionala priser och ersättningar för södra sjukvårdsregionen 2018, 2017-11-30 2017 [Available from: http:// sodrasjukvardsregionen.se/avtal-priser/regionala-priser-och-ersattningar/. Accessed 12 Feb 2018

19. FASS (Pharmaceuticals Specialties in Sweden). 2018. Available from: http:// www.fass.se/

20. Drummond MF, Schulpher MJ, Torrance GW, O'Brien BJ, Stoddart GL (2005) Methods for the economic evaluation of health care Programmes. Oxford University Press, New York

21. Devlin NJ, Shah KK, Feng Y, Mulhern B, van Hout B (2018) Valuing health-related quality of life: an EQ-5D-5L value set for England. Health Econ 27(1):7-22

22. Dolan P, Gudex C, Kind P, Williams A (1995) A social tariff for EuroQol: results from a UK general population study. In: Discussion paper 138. Centre for Health Economics, University of York, York

23. Burstrom K, Johannesson M, Diderichsen F (2001) Swedish population health-related quality of life results using the EQ-5D. Qual Life Res 10(7):621-635

24. Burstrom K, Sun S, Gerdtham UG, Henriksson M, Johannesson M, Levin LA et al (2014) Swedish experience-based value sets for EQ-5D health states. Qual Life Res 23(2):431-442

25. QRC Stockholm. Värderingssystem för EQ-5D-5L 2018 [Available from: https://arcstockholm.se/wp-content/uploads/2018/11/RapportV\%C3\%A4rderingssystem-slutlig.pdf. Accessed 9 Apr 2019.

Ready to submit your research? Choose BMC and benefit from:

- fast, convenient online submission

- thorough peer review by experienced researchers in your field

- rapid publication on acceptance

- support for research data, including large and complex data types

- gold Open Access which fosters wider collaboration and increased citations

- maximum visibility for your research: over $100 \mathrm{M}$ website views per year

At BMC, research is always in progress.

Learn more biomedcentral.com/submissions 